\title{
Reduced pulmonary vascular reserve during stress echocardiography in confirmed pulmonary hypertension and patients at risk of overt pulmonary hypertension
}

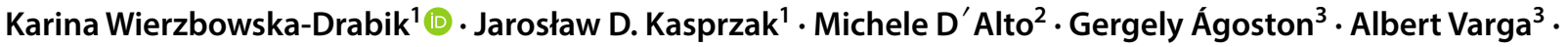 \\ Francesco Ferrara ${ }^{4} \cdot$ Miguel Amor $^{5} \cdot$ Quirino Ciampi $^{6} \cdot$ Eduardo Bossone $^{7} \cdot$ Eugenio Picano $^{8}$
}

Received: 10 April 2020 / Accepted: 21 May 2020 / Published online: 27 May 2020

(c) The Author(s) 2020

\begin{abstract}
Noninvasive estimation of systolic pulmonary artery pressure (SPAP) during exercise stress echocardiography (ESE) is recommended for pulmonary hemodynamics evaluation but remains flow-dependent. Our aim was to assess the feasibility of pulmonary vascular reserve index (PVRI) estimation during ESE combining SPAP with cardiac output (CO) or exercise-time and compare its value in three group of patients: with invasively confirmed pulmonary hypertension $(\mathrm{PH})$, at risk of $\mathrm{PH}$ development (PH risk) mainly with systemic sclerosis and in controls (C) without clinical risk factors for $\mathrm{PH}$, age-matched with PH risk patients. We performed semisupine ESE in 171 subjects: $31 \mathrm{PH}, 61 \mathrm{PH}$ at risk and 50 controls as well as in 29 young, healthy normals. Rest and stress assessment included: tricuspid regurgitant flow velocity (TRV), pulmonary acceleration time (ACT), CO (Doppler-estimated). SPAP was calculated from TRV or ACT when TRV was not available. We estimated PVRI based on CO (peak CO/SPAP*0.1) or exercise-time (ESE time/SPAP*0.1). During stress, TRV was measurable in 44\% patients ACT in 77\%, either one in 95\%. PVRI was feasible in 65\% subjects with CO and $95 \%$ with exercise-time $(\mathrm{p}<0.0001)$. PVRI was lower in PH compared to controls both for CO-based PVRI (group $1=1.0 \pm 0.95$ vs group $3=4.28 \pm 2.3, \mathrm{p}<0.0001)$ or time-based PVRI estimation $(0.66 \pm 0.39$ vs $3.95 \pm 2.26, \mathrm{p}<0.0001)$. The proposed criteria for PH detection were for CO-based PVRI $\leq 1.29$ and ESE-time based PVRI $\leq 1.0$ and for PH risk $\leq 1.9$ and $\leq 1.7$ respectively. Noninvasive estimation of PVRI can be obtained in near all patients during ESE, without contrast administration, integrating TRV with ACT for SPAP assessment and using exercise time as a proxy of CO. These indices allow for comparison of pulmonary vascular dynamics in patients with varied exercise tolerance and clinical status.
\end{abstract}

Keywords Pulmonary hypertension $\cdot$ Stress echocardiography $\cdot$ Pulmonary vascular reserve $\cdot$ Tricuspid regurgitant velocity $\cdot$ Pulmonary acceleration time

On behalf of Stress Echo 2020 study group of the Italian Society of Echocardiography andCardiovascular Imaging (SIECVI).

Karina Wierzbowska-Drabik

wierzbowska@ptkardio.pl

1 I Department and Chair of Cardiology, Medical University of Lodz, Bieganski Hospital, Lodz, Poland

2 Department of Cardiology, University “L. Vanvitelli”- AORN dei Colli - Monaldi Hospital, Naples, Italy

3 Department of Family Medicine, University of Szeged, Tisza Lajos krt. 109, Szeged 6725, Hungary

4 Cardiology Division, Heart Department, University Hospital of Salerno, "Cava de' Tirreni and Amalfi Coast" Hospital, Salerno, Italy
5 Cardiology Department, Ramos Mejia Hospital, Buenos Aires, Argentina

6 Division of Cardiology, Fatebenefratelli Hospital, Benevento, Italy

7 AORN A. Cardarelli Hospital, Naples, Italy

8 Institute of Clinical Physiology - C.N.R., Pisa, Italy 


$\begin{array}{ll}\begin{array}{l}\text { Abbreviations } \\ \text { ACT }\end{array} & \begin{array}{l}\text { Acceleration time of physiologic sys- } \\ \text { tolic forward pulmonary flow velocity } \\ \text { Cardiac output }\end{array} \\ \text { CO } & \begin{array}{l}\text { CO based pulmonary vascular reserve } \\ \text { index }\end{array} \\ \text { CO/SPAP } & \text { Exercise stress echocardiography } \\ \text { ESE } & \begin{array}{l}\text { ESE time based pulmonary vascular } \\ \text { reserve index }\end{array} \\ \text { ESE time/SPAP } & \text { Pulmonary arterial hypertension } \\ \text { PAH } & \text { Pulmonary hypertension } \\ \text { PH } & \text { Pulmonary vascular reserve index } \\ \text { PVRI } & \text { Right atrial pressure } \\ \text { RAP } & \text { Systolic pulmonary artery pressure } \\ \text { SPAP } & \text { Acronym for using TRV and ACT for } \\ \text { TRACT } & \text { SPAP estimation } \\ \text { TRV } & \text { Tricuspid regurgitant velocity } \\ \text { TTE } & \text { Transthoracic echocardiography }\end{array}$

\section{Introduction}

The disproportionate increase in pulmonary artery pressure during exercise is probably a precursor to pulmonary hypertension $(\mathrm{PH})$ at rest $[1,2]$. The early detection of $\mathrm{PH}$ is especially important in patients belonging to group 1 by the updated clinical classification of $\mathrm{PH}$, including relatives of patients with diagnosed PAH (pulmonary arterial hypertension) as well as $\mathrm{PH}$ associated to other diseases such as systemic sclerosis [1-4]. These patients presents high risk of PH development, assessed for $8 \%$ to $12 \%$, and earlier therapy may improve their outcomes [5].

Nevertheless, noninvasive, echocardiographic assessment of systolic arterial pulmonary pressure (SPAP) has the intrinsic limitation of being flow-dependent and in such a way by definition workload- related [1]. In spite of the many advantages as a noninvasive, available, radiationfree technique, the use of exercise stress echocardiography (ESE) has remained limited to date, mostly for technical problems of sampling tricuspid regurgitant velocity (TRV) during exercise [6] and the conceptual limitation of estimating pulmonary hemodynamics with a flow-dependent index such as SPAP, loosing moreover its close relationship with pulmonary pressure in most advanced tricuspid regurgitation [1-7]. The feasibility problem of TRV may, however, be minimized by measuring the acceleration time (ACT) of physiologic forward systolic pulmonary flow velocity, also present when TRV is unfeasible and estimating SPAP with a combined TRACT (tricuspid regurgitation + acceleration time) approach $[8,9]$.

The feature of pathologic increase of SPAP during exercise is its disproportion to the cardiac output (CO) augmentation and abnormal response of pulmonary vascular resistance. It has been estimated that normal pulmonary vascular response is related with the increase of mean pulmonary arterial pressure in the range of $1-2 \mathrm{mmHg}$ per $1 \mathrm{l} /$ min augmentation of $\mathrm{CO}$ [10]. Recently, the noninvasive assessment of similar parameter was proposed since the $\mathrm{CO}$ can be estimated from 2D volumetric echocardiography or preferably by Doppler, or even through the proxy of minutes of exercise [11].

The hypothesis of the present study is that in its refined version, ESE can solve the two major problems of suboptimal success rate for SPAP estimation as well as the limited discriminatory capacity of flow-dependent parameters.

The primary aim of our study was to assess in a multicenter, prospective design the feasibility of pulmonary vascular reserve index (PVRI) based either on $\mathrm{CO}(\mathrm{CO} /$ SPAP*0.1 at peak stress) or on simpler, imaging-independent exercise time (ESE time/SPAP*0.1 at peak stress). The secondary aim was to evaluate the value of these parameters in differentiating pulmonary hemodynamic patterns in patients with either confirmed $\mathrm{PH}$ or at risk for $\mathrm{PH}$ development compared to an age-matched control group.

\section{Methods}

The study was performed as the part of the multicentre project $[12,13]$ and its protocol was reviewed and approved by the institutional ethics committees as a part of the SE 2020 study (148-Comitato Etico Lazio-1, July 16, 2016; Clinical trials. Gov Identifier NCT 030.49995). All patients gave informed consent to enter the study.

\section{Study group}

We included 142 subjects, 96 women, mean age $55 \pm 15$ years (from 19 to 88 ) from six centers, without the contraindications to exercise referred to ESE for the assessment of exercise tolerance as well as for CAD diagnosis/exclusion. As PH group we examined 31 consecutive patients with diagnosed, treated and monitored $\mathrm{PH}$ as confirmed with mPAP $>25 \mathrm{mmHg}$ assessed by right heart catheterization whose were amenable to exercise tolerance assessment with ESE.

Into $\mathrm{PH}$ risk group we included 61 subjects with systemic sclerosis (56 subjects) or mixed connective tissue disease (five patients) and as a control group 50 age-matched subjects without risk factors of PH but with present risk factors for cardiovascular disease although without diagnosed coronary artery disease. Additionally we evaluated also the group of 29 young, healthy subjects, without risk factors for cardiovascular diseases, whose data were used for establishing the normal values of tested parameters (PVRI CO and ESE time based). 


\section{Echocardiographic assessment}

Transthoracic echocardiography at rest and ESE was performed with E9 (GE, Vingmed, Norway) or VIVID 7 (GE Vingmed Ultrasound AS, Horten, Norway) systems using M4S/M5S probes. During the echocardiography an ECG tracing was displayed on the monitor. The echocardiographic measurements (including Doppler parameters) were taken following the recommendations [6, 14-16].

\section{Assessment of TRV and ACT}

TRV was derived with continuous wave Doppler from the apical four chamber or the parasternal right ventricular inflow view. The right ventricular systolic pressure was assumed to equal SPAP, and was calculated with the Bernoulli equation ( $\mathrm{TRV}$ in $\mathrm{m} / \mathrm{s})$ : $\mathrm{SPAP}=4 \mathrm{TRV}^{2}+$ right atrial pressure (RAP). RAP was estimated from the inferior vena cava (IVC) diameter and collapsing during the inspiration. We added RAP of $3 \mathrm{~mm} \mathrm{Hg}$ (IVC diameter $<2.1 \mathrm{~cm}$, collapsing $>50 \%$ with a sniff), or $15 \mathrm{~mm} \mathrm{Hg}$ (diameter $>2.1 \mathrm{~cm}$, collapsing $\leq 50 \%$ with a sniff) or $8 \mathrm{~mm} \mathrm{Hg}$ in mixed scenarios. The value calculated at rest was applied also at stress $[6,17]$.

ACT was measured in right ventricular outflow tract as the time (in milliseconds) from the beginning of pulmonary ejection until the peak value of systolic velocity. Pulsed wave Doppler was used with sample positioned at the annulus of the pulmonary artery, in the parasternal short axis or in the subcostal view. The normal value is $>110 \mathrm{~ms}$, the abnor$\mathrm{mal}<105$, and indeterminate-between 105 and $110 \mathrm{~ms}$ [18]. From the raw data of ACT, SPAP was derived on the basis of the correlation linking ACT to TRV as follows: $\log _{10}$ $\mathrm{SPAP}=-0.004(\mathrm{ACT})+2.1[19]$.

\section{Exercise stress echocardiography}

All patients underwent semi-supine bicycle ESE as described by recent recommendations [14]. The study protocol combining TRV and ACT assessment (TRACT) is displayed in Fig. 1. ESE was performed at an initial workload of 25 Watts lasting for $2 \mathrm{~min}$, then the workload increased stepwise by 25 Watts at 2 -min intervals. Electrocardiogram and blood pressure were monitored and all studies were performed by cardiologists experienced in different kind of stress echo examinations and analysis assisted by the nurses or the doctors. Criteria for interrupting the test were chest pain, induced wall motion abnormalities, significant rhythm disturbances, excessive fatigue, blood pressure increase (systolic $\geq 240 \mathrm{mmHg}$, diastolic $\geq 120 \mathrm{mmHg}$ ), limiting dyspnea, legs pain or predicted heart rate. Video loops of heart cycles were acquired and digitally stored for further analysis. All echocardiographers had passed quality control of reading examinations as required by Stress Echo 2020 study with interobserver reproducibility $\geq 90 \%$ [20]. CO was derived
Fig. 1 The study protocol with assessment of TRV and ACT for SPAP estimation, and cardiac output with Doppler/2D method. Exercise time is also recorded. $A C T$ acceleration time, $B P$ blood pressure, $C O$ cardiac output, $C W$ continuous wave, $E C G$ electrocardiogram, LVOT left ventricular outflow tract, $P L A X$ parasternal long axis view, $P W$ pulsed wave, $S E$ stress echocardiography, TRACT acronym from tricuspid regurgitation/acceleration time, $T R V$ tricuspid regurgitant velocity, $V T I$ velocity time integral

\section{Doppler/2D SE: TRACT Protocol plus CO estimation}

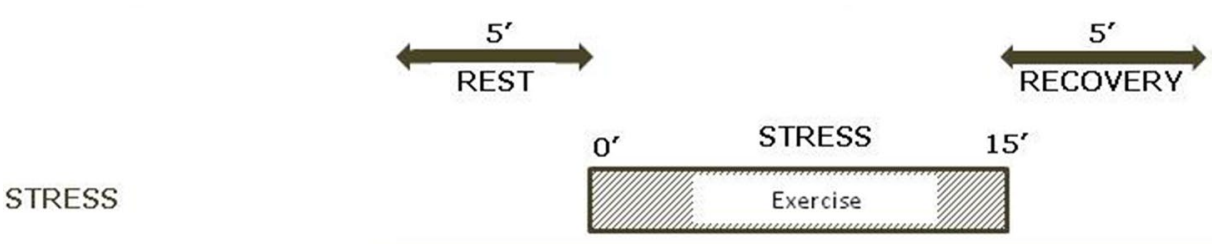

Doppler (CW)

Doppler (PW)

CW-Doppler: TRV

PW-Doppler: ACT/LVOT VTI

2D: PLAX

LVOT/apical views

BP (cuff sphygmo)

ECG (12-lead recording)

ECG (on monitor)
V v ఐ V

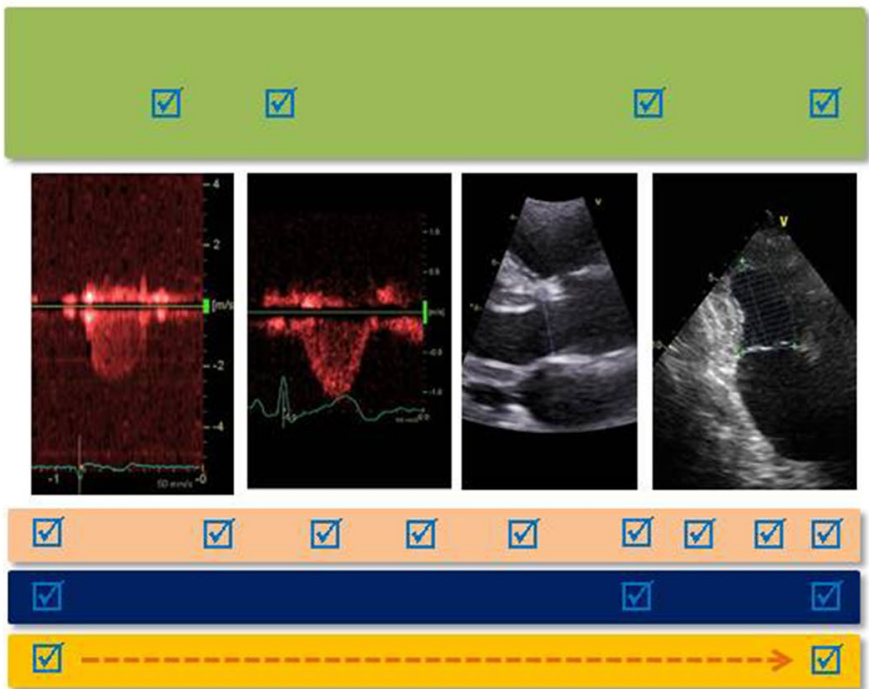


from the Doppler-estimated stroke volume (SV) using the velocity time integral of flow through the left ventricular outflow tract [21-25]. Pulmonary vascular resistance (PVR) was calculated using Abbas formula: $P V R$ $($ Wood Units $)=T R V(\mathrm{~m} / \mathrm{s}) / V T I R V O T(\mathrm{~cm}) * 10+0.16$ and assessed separately in two time points at baseline and peak exercise [26, 27].

As relatively flow-independent SPAP derived parameter we modified and simplified those proposed by Claessens: SPAP/CO slope (requiring two points, rest and peak, and slope calculation) was modified into CO/peak SPAP*0.1; SPAP/exercise intensity was modified into ESE time/peak SPAP*0.1 [11]. Pulmonary vascular reserve index (PVRI) was estimated as CO-based (CO-PVRI) or as exercise-timebased (ESE time-PVRI). ESE-time was defined as time in minutes from beginning to the peak of exercise. Higher values of these parameters may reflect better pulmonary vascular reserve.

We added three figures as case-illustrating graphics. Figure 2 presents TRV and ACT rest and stress measurements done in healthy 43-old-year female whereas in Fig. 3 respective parameters are displayed in 63-year-old man with diagnosed pulmonary hypertension. Figure 4 illustrates the comparison of PVRI expressed as slopes of delta SPAP in relations to ESE time. The lines illustrate respectively an normal flat response (with high PVRI) and a steep impaired response, with low PVRI value.

\section{Statistical analysis}

Data are expressed as mean \pm standard deviation for continuous or frequency for categorical data. The distribution was assessed with the D'Agostino-Pearson test and adequate tests were used. For correlation Pearson's or Spearman coefficients were calculated. The comparisons were performed with t-test for independent samples or paired t-test, Wilcoxon test or chi-squared test for categorical data. Statistical significance was set at $p<0.05$. ROC analysis was applied for detection of cut-off values for studied parameters. Analyses were conducted with MedCalc V. 12.1.4. (Frank Schoonjans Belgium).

\section{Results}

The clinical characteristics and hemodynamic data related to ESE of the patients and controls are listed in Table 1. In patients with diagnosed $\mathrm{PH} 11$ had idiopathic PAH, 8 congenital heart disease related $\mathrm{PH}, 6$ connective tissue related $\mathrm{PH}$ and 6 chronic thromboembolic $\mathrm{PH}$. In $\mathrm{PH}$ at risk group,

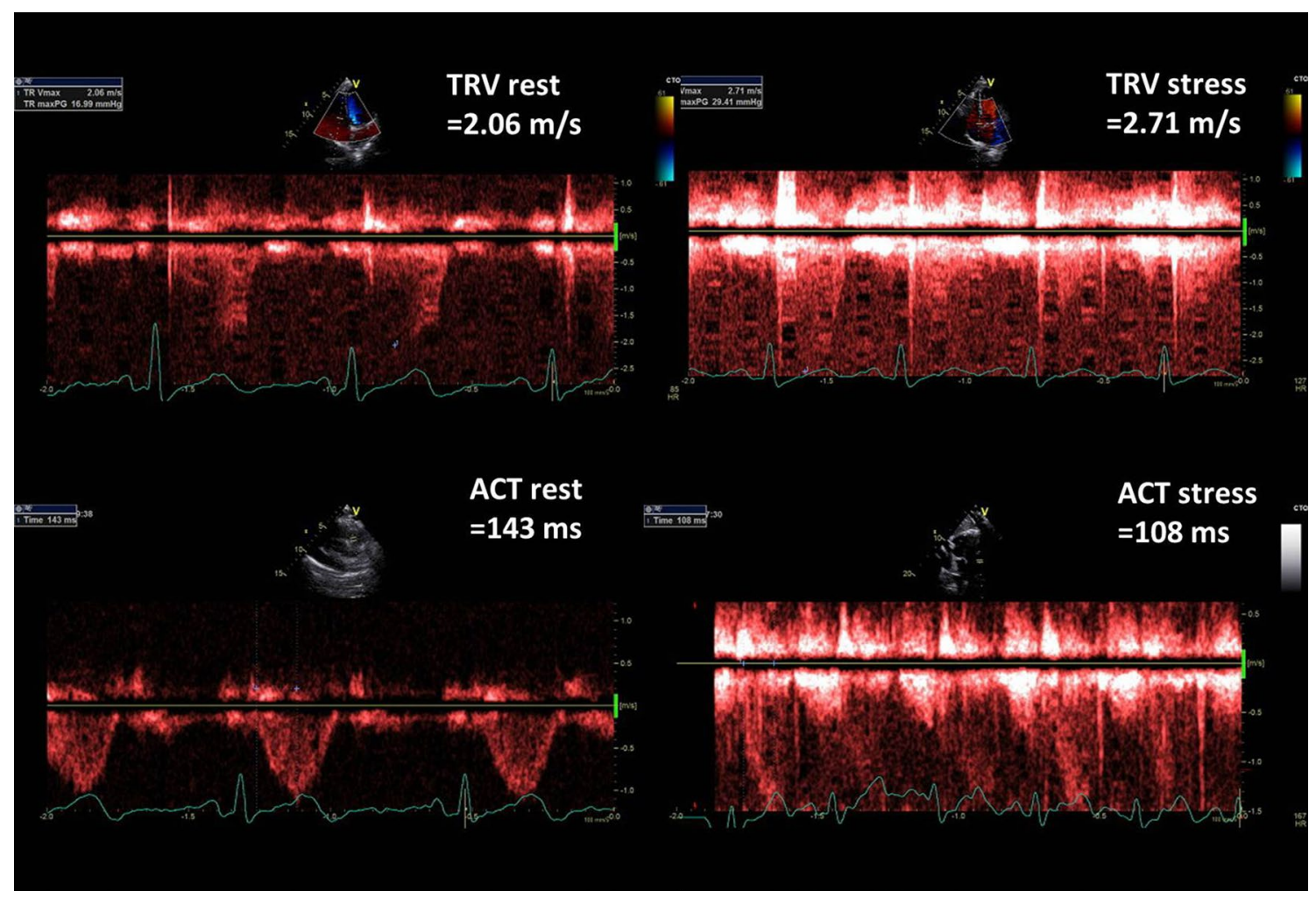

Fig. 2 Graphic presentation of TRV and ACT measurements at baseline and peak stress in 43-year-old woman with very good exercise tolerance and high normal PVRI, calculated as the ratio of ESE time and $\triangle$ SPAP in tens; PVRI $=14 \mathrm{~min} / 1.3=10.8$ 


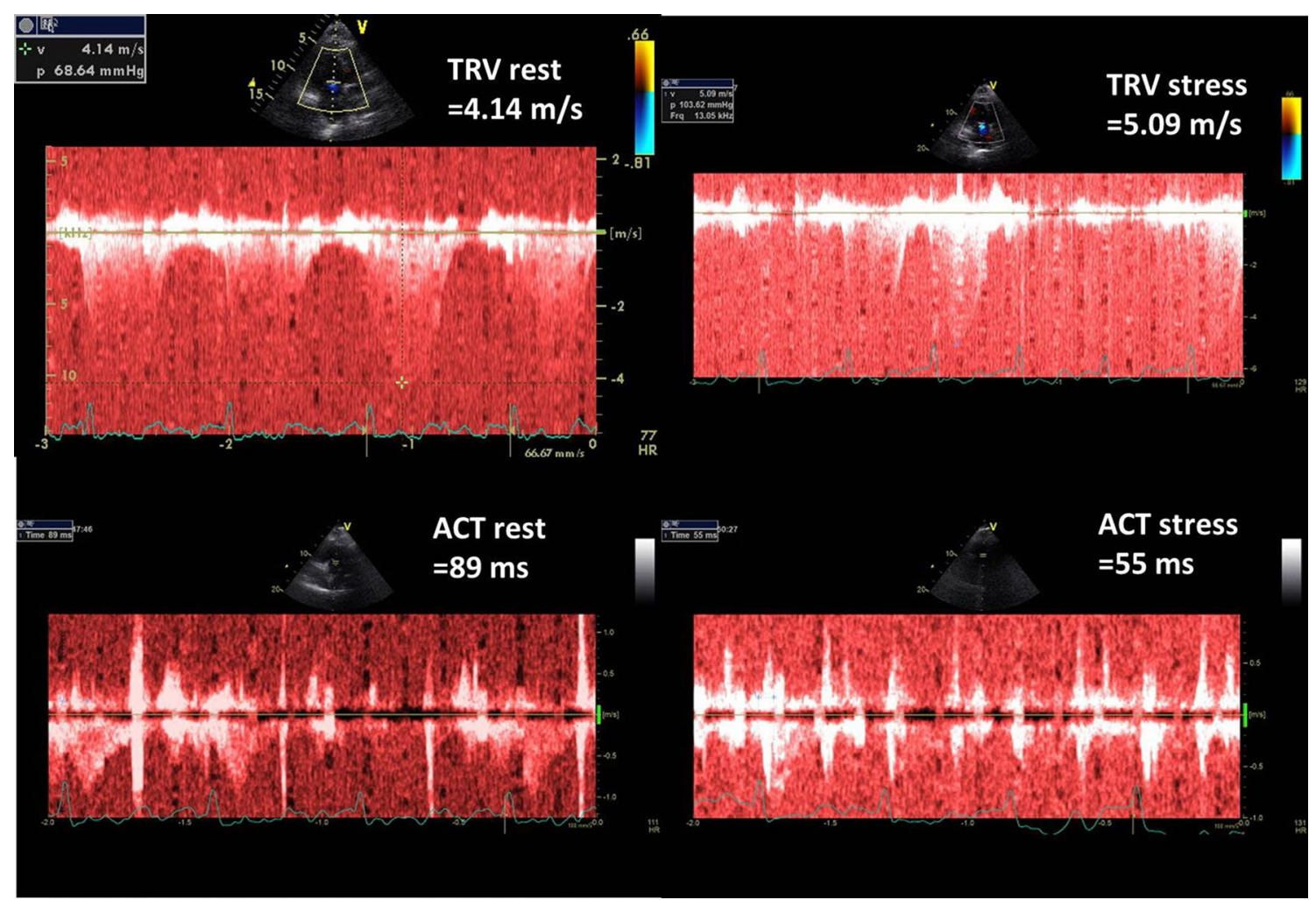

Fig. 3 Graphic presentation of TRV and ACT measurements at baseline and peak stress in 63-year-old man with poor exercise tolerance and highly abnormal PVRI, calculated as the ratio of ESE time and $\triangle \mathrm{SPAP}$ in tens; PVRI $=3 \mathrm{~min} / 3.5=0.9$

Fig. 4 Graphic comparison of PVRI data representive for healthy subject with high value of PVRI and flat increase of SPAP during exercise and abnormal steep time-pressure relationship in patient with $\mathrm{PH}$ of diagnosed chronić thromboembolic origin

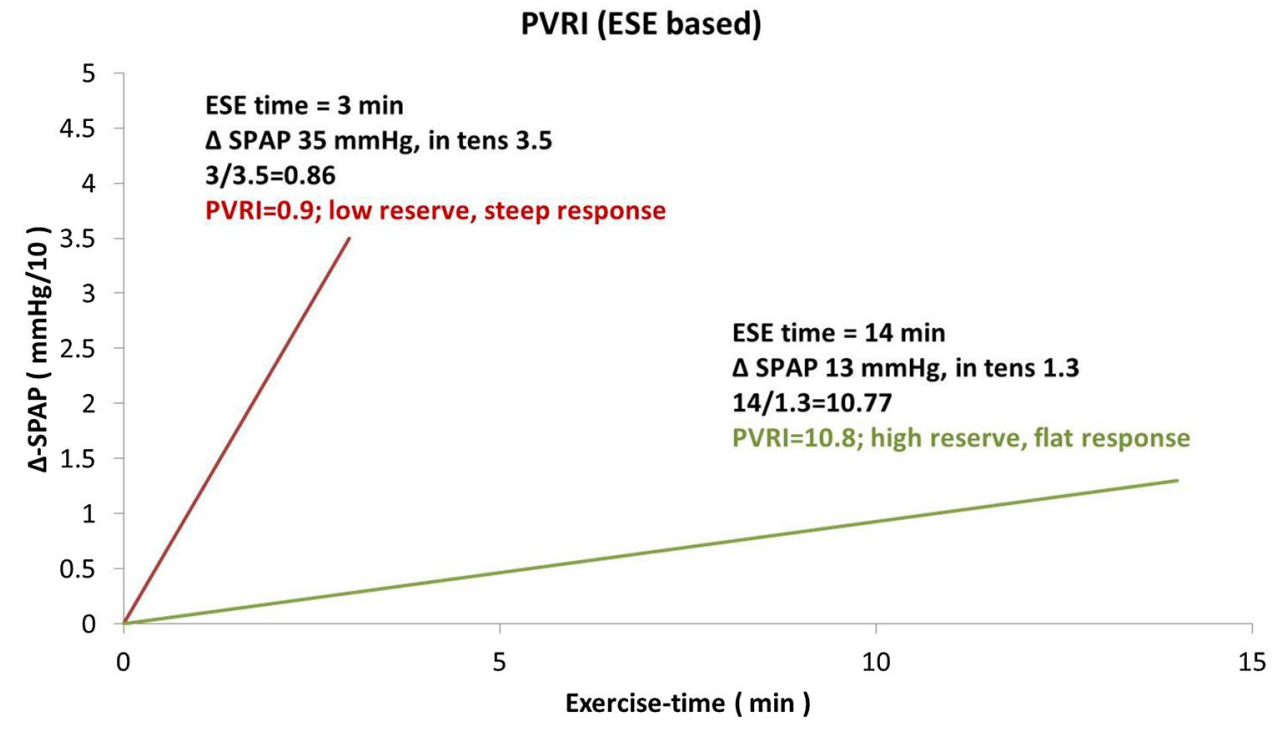

associated disease was systemic sclerosis in 56 patients, and mixed connective tissue disease in five patients.

The groups did not differ according to mean age, body mass index and the prevalence of hypertension and diabetes, nevertheless in PH risk group higher prevalence of women as well as smaller mean body surface area were observed. Contrary to both $\mathrm{PH}$ at risk and control group no patients with confirmed $\mathrm{PH}$ smoked.

The achieved workload as well as exercise duration $(10.6 \pm 3.3$ vs $6.4 \pm 1.9$ vs $5.6 \pm 1.6 \mathrm{~min})$ were greater in controls as compared with $\mathrm{PH}$ risk and $\mathrm{PH}$ and was 
Table 1 Clinical and hemodynamics characteristics of the patients

\begin{tabular}{|c|c|c|c|c|c|c|}
\hline Variable & $\begin{array}{l}\text { Group } 1 \\
\mathrm{PH}, \mathrm{N}=31\end{array}$ & $\begin{array}{l}\text { Group } 2 \\
\text { PH risk, } \mathrm{N}=61\end{array}$ & $\begin{array}{l}\text { Group } 3 \\
\text { controls, } \mathrm{N}=50\end{array}$ & $\begin{array}{l}\mathrm{p} \\
1 \text { vs } 2\end{array}$ & $\begin{array}{l}\mathrm{p} \\
2 \text { vs } 3\end{array}$ & $\begin{array}{l}\mathrm{p} \\
1 \text { vs } 3\end{array}$ \\
\hline Age (years) & $\begin{array}{l}56 \pm 18 \\
(19-87)\end{array}$ & $\begin{array}{l}57 \pm 15 \\
(19-80)\end{array}$ & $\begin{array}{l}52 \pm 14 \\
(21-88)\end{array}$ & ns & ns & ns \\
\hline Sex (males/females, males \%) & $\begin{array}{l}14 / 17 \\
(45 \%)\end{array}$ & $\begin{array}{l}9 / 52 \\
(15 \%)\end{array}$ & $\begin{array}{l}23 / 27 \\
(46 \%)\end{array}$ & 0.0039 & 0.0007 & ns \\
\hline $\operatorname{BSA}\left(\mathrm{m}^{2}\right)$ & $\begin{array}{l}1.84 \pm 0.2 \\
(1.44-2.44)\end{array}$ & $\begin{array}{l}1.75 \pm 0.2 \\
(1.4-2.64)\end{array}$ & $\begin{array}{l}1.91 \pm 0.2 \\
(1.43-2.44)\end{array}$ & 0.044 & 0.0001 & ns \\
\hline Body mass index $\left(\mathrm{kg} / \mathrm{m}^{2}\right)$ & $\begin{array}{l}26 \pm 4.8 \\
(18.5-36.5)\end{array}$ & $\begin{array}{l}26.8 \pm 4.9 \\
(18.4-37.2)\end{array}$ & $\begin{array}{l}26.5 \pm 4.4 \\
(18.9-39.3)\end{array}$ & ns & ns & ns \\
\hline Hypertension & $13(42 \%)$ & $30(49 \%)$ & $17(34 \%)$ & ns & ns & ns \\
\hline Diabetes & $3(10 \%)$ & $4(5 \%)$ & $2(4 \%)$ & ns & ns & ns \\
\hline Smoking & $0(0 \%)$ & $18(30 \%)$ & $8(16 \%)$ & 0.0017 & ns & 0.0497 \\
\hline ACE-I & $13(42 \%)$ & $13(21 \%)$ & $15(30 \%)$ & ns & ns & ns \\
\hline $\mathrm{CCB}$ & $5(16 \%)$ & $20(33 \%)$ & $3(6 \%)$ & ns & 0.0012 & ns \\
\hline Diuretics & $22(71 \%)$ & $22(36 \%)$ & $7(14 \%)$ & 0.0031 & 0.016 & $<0.0001$ \\
\hline HR rest (bpm) & $\begin{array}{l}75 \pm 14 \\
(48-110)\end{array}$ & $\begin{array}{l}79 \pm 12 \\
(55-120)\end{array}$ & $\begin{array}{l}68 \pm 13 \\
(48-100)\end{array}$ & ns & $<0.0001$ & 0.0249 \\
\hline HR peak (bpm) & $\begin{array}{l}119 \pm 19 \\
(85-173)\end{array}$ & $\begin{array}{l}130 \pm 17 \\
(90-170)\end{array}$ & $\begin{array}{l}131 \pm 22 \\
(78-170)\end{array}$ & 0.0059 & ns & 0.0141 \\
\hline DBP rest $(\mathrm{mmHg})$ & $\begin{array}{l}80 \pm 11 \\
(61-106)\end{array}$ & $\begin{array}{l}75 \pm 10 \\
(50-100)\end{array}$ & $\begin{array}{l}81 \pm 14 \\
(51-115)\end{array}$ & 0.031 & 0.0098 & ns \\
\hline DBP peak $(\mathrm{mmHg})$ & $\begin{array}{l}91 \pm 17 \\
(43-127)\end{array}$ & $\begin{array}{l}88 \pm 15 \\
(69-141)\end{array}$ & $\begin{array}{l}96 \pm 21 \\
(65-181)\end{array}$ & $\mathrm{ns}$ & 0.0213 & ns \\
\hline SBP rest $(\mathrm{mmHg})$ & $\begin{array}{l}128 \pm 20 \\
(96-169)\end{array}$ & $\begin{array}{l}123 \pm 16 \\
(80-160)\end{array}$ & $\begin{array}{l}134 \pm 19 \\
(97-174)\end{array}$ & ns & 0.0013 & ns \\
\hline SBP peak $(\mathrm{mmHg})$ & $\begin{array}{l}157 \pm 30 \\
(99-224)\end{array}$ & $\begin{array}{l}161 \pm 25 \\
(126-230)\end{array}$ & $\begin{array}{l}182 \pm 31 \\
(122-240)\end{array}$ & $\mathrm{ns}$ & 0.0001 & 0.0006 \\
\hline $\mathrm{O}_{2}$ saturation rest & $\begin{array}{l}91 \pm 8 \\
(70-99)\end{array}$ & $\begin{array}{l}96 \pm 3.4 \\
(88-99)\end{array}$ & $\begin{array}{l}97 \pm 1.7 \\
(93-99)\end{array}$ & 0.0001 & $\mathrm{~ns}$ & $<0.0001$ \\
\hline $\mathrm{O}_{2}$ saturation peak & $\begin{array}{l}83 \pm 13 \\
(55-100)\end{array}$ & $\begin{array}{l}94 \pm 5.6 \\
(78-99)\end{array}$ & $\begin{array}{l}96 \pm 2.9 \\
(81-100)\end{array}$ & $<0.0001$ & 0.0242 & $<0.0001$ \\
\hline Workload (Watt) & $\begin{array}{l}70 \pm 20 \\
(50-100)\end{array}$ & $\begin{array}{l}86 \pm 24 \\
(45-150)\end{array}$ & $\begin{array}{l}133 \pm 42 \\
(50-200)\end{array}$ & 0.002 & $<0.0001$ & $<0.0001$ \\
\hline Exercise time (min) & $\begin{array}{l}5.6 \pm 1.6 \\
(4-8)\end{array}$ & $\begin{array}{l}6.8 \pm 2 \\
(4-12)\end{array}$ & $\begin{array}{l}10.6 \pm 3.3 \\
(4-16)\end{array}$ & 0.0047 & $<0.0001$ & $<0.0001$ \\
\hline Tiredness in Borg Scale & $\begin{array}{l}7.8 \pm 1.3 \\
(4-100)\end{array}$ & $\begin{array}{l}5.3 \pm 1.8 \\
(3-10)\end{array}$ & $\begin{array}{l}7.6 \pm 0.7 \\
(6-9)\end{array}$ & $<0.0001$ & $<0.0001$ & ns \\
\hline
\end{tabular}

$A C E-I$ inhibitors of angiotensin converting enzyme, $B S A$ body surface area, $C C B$ calcium channel blockers, $P H$ pulmonary arterial hypertension, $D B P$ diastolic blood pressure, $S B P$ systolic blood pressure, $H R$ heart rate, $P H$ pulmonary arterial hypertension

reflected also in more elevated peak systolic pressure $(182 \pm 31$ vs $161 \pm 25$ vs $157 \pm 30 \mathrm{mmHg})$.

For the variability assessment of echocardiographic parameters we calculated intraclass correlation coefficient. Intraobserver variability achieved for ACT at rest 0.96 and for TRV 0.99, whereas for the peak parameters these values were 0.89 for ACT and 0.96 for TRV, as we previously reported [9].

In Table 2 the feasibility of echocardiographic parameters is displayed showing for peak of ESE $44 \%$ of TRV feasibility, 77\% for ACT and 95\% for SPAP estimation based on both TRV and ACT according to TRACT protocol.
Similarly, the application of ESE time in the place of CO enabled the significant feasibility improvement of PVRI from 65 to $95 \%$, p $<0.0001$, see Fig. 5 .

In Table 3 the comparison of echocardiographic parameters in all three groups showed the consistent differences for parameters reflecting pulmonary pressure, resistance and reserve indicating the most advanced impairment of pulmonary circulation status in $\mathrm{PH}$ group, intermediate stage in $\mathrm{PH}$ risk patients and normal or near-normal values in age-matched controls. Additionally we estimated also the both PVRI parameters in 29 healthy, young patients (mean age $32 \pm 5.3$ years, 21 males, cardiovascular risk factors 
Table 2 Echocardiographic findings: feasibility expressed as number and percentage

\begin{tabular}{lcl}
\hline Parameter & $\begin{array}{l}\text { Number in the } \\
\text { whole group of } \\
142 \text { pts }\end{array}$ & $\begin{array}{l}\text { (\%) in the } \\
\text { whole group }\end{array}$ \\
\hline Rest TRV & 80 & 56 \\
Rest ACT & 117 & 82 \\
Peak TRV & 62 & 44 \\
Peak ACT & 109 & 77 \\
SPAP (TRV based) rest & 80 & 56 \\
SPAP (TRV based) peak & 62 & 44 \\
SPAP rest (TRV + ACT based) & 138 & 97 \\
SPAP peak (TRV + ACT based) & 135 & 95 \\
PV Resistance rest (Wood U) & 79 & 56 \\
PV Resistance peak (Wood U) & 60 & 42 \\
CO-based PVRI & 92 & 65 \\
ESE time- based PVRI & 135 & 95
\end{tabular}

$C O$ cardiac output, ESE exercise stress echocardiography, $P V$ resistance pulmonary vascular resistance, calculated according to Abbas formula: PV Resistance (Wood Units) $=$ TRV $(\mathrm{m} / \mathrm{s}) /$ VTI RVOT $(\mathrm{cm})$ $* 10+0.16$. PVRI pulmonary vascular reserve index, TRV tricuspid regurgitant velocity, $A C T$ acceleration time of pulmonary flow, SPAP systolic pulmonary artery pressure
Peak SPAP (TRV)

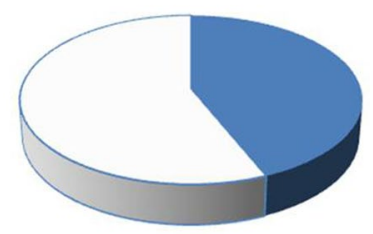

CO-based PVRI

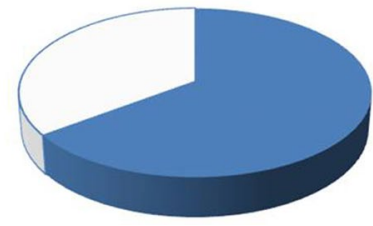

Peak SPAP (TRV + ACT)

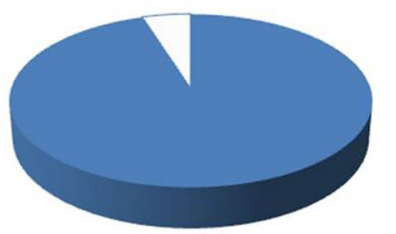

ESE time- based PVRI

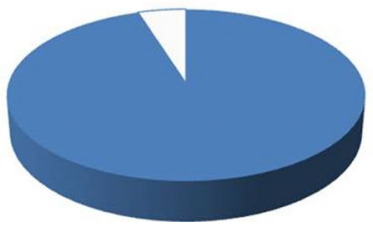

Fig. 5 Graphic presentation of the feasibility of echocardiographic parameters in the whole studied group. Including the ACT as an alternative parameters for SPAP estimation increased feasibility of stress SPAP obtaining from 44 to $95 \%$. Similarly, the substitution of CO with ESE time increased feasibility for flow-independent indices from 65 to $95 \%$. ACT acceleration time, $C O$ cardiac output, ESE exercise stress echocardiography, $P V R I$ pulmonary vascular reserve index, $S P A P$ systolic pulmonary artery pressure, $T R V$ tricuspid regurgitant velocity. Blue colour - feasible data, white — unfeasible data; feasibility results: Peak SPAP $($ TRV based $)=44 \%$, Peak SPAP $($ TRV + ACT based $)=95 \%$ CO based PVRI $=65 \%$, ESE time-based PVRI $=95 \%$

including smoking and obesity excluded) obtaining reference, normal values of $5.26 \pm 2.9 \mathrm{~L} / \mathrm{min} / \mathrm{mmHg}$ for CObased PVRI and $5.03 \pm 2.59(\mathrm{~min} / \mathrm{mmHg})$ for ESE timebased PVRI.
Moreover, in the analysis focused on the comparison between patients at risk of $\mathrm{PH}$ and controls (group 2 and 3) all resting parameters: TRV, ACT, SPAP and PVR were similar in both compared groups, whereas variables measured at peak stage of ESE (apart from pulmonary vascular resistance, PVR) revealed higher values of TRV and SPAP and shorter ACT in patient with risk factors for $\mathrm{PH}$, as well as significantly higher PVRI (either CO-based or exercisetime-based) in controls, see Fig. 6.

Having the subgroup of invasively proved diagnosis of $\mathrm{PH}$ (31 patients) we estimated from ROC analysis cut-off values for flow dependent and independent parameters. The results are displayed in Table 4. Estimated cut-off values were tested in group at risk of PH development. The best cut-off values were: > $62 \mathrm{mmHg}$ for SPAP, TRV-based; $>69 \mathrm{mmHg}$ for SPAP, TRACT-based; $\leq 1.29$ for CO-based PVRI; and $\leq 1$ for ESE time- based PVRI.

Moreover, we tried to estimate also the cut offs for diagnosis $\mathrm{PH}$ risk patients among subgroup consisted of $\mathrm{PH}$ at risk and age - matched controls and found the values $\leq 1.9$ for CO-based PVRI; and $\leq 1.7$ for ESE time- based PVRI with respective ROC AUC of 0.917 and 0.824 .

The relationship between peak SPAP calculated according to TRACT approach and ESE-time based PVRI is displayed in Fig. 7 illustrating non-linear relationship between both parameters and high discriminatory value for three examined subgroups.

\section{Discussion}

Noninvasive estimates of PVRI expressed as indices based on $\mathrm{CO}$ or exercise-time can be obtained during exercise with moderate (CO-based) or excellent (ESE-time based) success rate, achieving 95\% feasibility for simplified data when avoiding CO calculation and utilizing beside TRV also ACT for SPAP calculation, Fig. 5. These PVRI parameters allow a clear discrimination of patients with $\mathrm{PH}$ or at risk for $\mathrm{PH}$ development as compared to control subjects as shown in Figs. 6 and 7. The significance of the pulmonary hemodynamic assessment at peak stress was especially pronounced when applied for detection of patients at risk of $\mathrm{PH}$, revealing similar values as controls at rest, see Fig. 6 . The application of indexed to flow indices seems to be more specific for accurate comparison of pulmonary vascular function between patients achieving highly varied level of exercise and related with this different peak cardiac output. In our study we observed significant percentage of patients achieving peak SPAP values between 40 and $60 \mathrm{mmHg}$ for which more flow independent indices seem to offer important additional discriminating value, see Fig. 7. The flow correction can be obtained with Doppler-based measurement of stroke volume and $\mathrm{CO}$ (which is the recommended method for the 
Table 3 Echocardiographic data comparison

\begin{tabular}{|c|c|c|c|c|c|c|}
\hline Parameter & $\begin{array}{l}\text { Group } 1 \\
\text { PH }\end{array}$ & Group 2 PH risk & $\begin{array}{l}\text { Group } 3 \\
\text { controls }\end{array}$ & $\begin{array}{l}\mathrm{p} \\
1 \text { vs } 2\end{array}$ & $\begin{array}{l}\mathrm{p} \\
2 \text { vs } 3\end{array}$ & $\begin{array}{l}\mathrm{s} \\
1 \text { vs } 3\end{array}$ \\
\hline Rest TRV $(\mathrm{cm} / \mathrm{s})$ & $\begin{array}{l}390 \pm 102 \\
(150-567)\end{array}$ & $\begin{array}{l}244+63 \\
(120-380)\end{array}$ & $\begin{array}{l}219 \pm 51 \\
(133-390)\end{array}$ & $<0.0001$ & ns & $<0.0001$ \\
\hline Rest ACT (ms) & $\begin{array}{l}68 \pm 18 \\
(42-129)\end{array}$ & $\begin{array}{l}112 \pm 32 \\
(54-177)\end{array}$ & $\begin{array}{l}112 \pm 23 \\
(65-175)\end{array}$ & $<0.0001$ & ns & $<0.0001$ \\
\hline Stress TRV $(\mathrm{cm} / \mathrm{s})$ & $\begin{array}{l}480 \pm 82 \\
(320-620)\end{array}$ & $\begin{array}{l}353 \pm 71 \\
(260-535)\end{array}$ & $\begin{array}{l}254 \pm 70 \\
(148-330)\end{array}$ & $<0.0001$ & 0.0001 & $<0.0001$ \\
\hline Stress ACT (ms) & $\begin{array}{l}59 \pm 18 \\
(28-111)\end{array}$ & $\begin{array}{l}84 \pm 20 \\
(41-120)\end{array}$ & $\begin{array}{l}95 \pm 21 \\
(65-152)\end{array}$ & $<0.0001$ & 0.0238 & $<0.0001$ \\
\hline SPAP (TRV based) rest & $\begin{array}{l}72 \pm 33 \\
(12-143)\end{array}$ & $\begin{array}{l}32 \pm 11 \\
(11-58)\end{array}$ & $\begin{array}{l}24 \pm 11 \\
(12-69)\end{array}$ & $<0.0001$ & 0.0137 & $<0.0001$ \\
\hline SPAP (TRV based) stress & $\begin{array}{l}110 \pm 32 \\
(56-169)\end{array}$ & $\begin{array}{l}55 \pm 24 \\
(29-129)\end{array}$ & $\begin{array}{l}33 \pm 14 \\
(15-50)\end{array}$ & $<0.0001$ & 0.0021 & $<0.0001$ \\
\hline SPAP rest (mmHg) & $\begin{array}{l}70 \pm 33 \\
(12-143)\end{array}$ & $\begin{array}{l}26 \pm 10 \\
(10-58)\end{array}$ & $\begin{array}{l}23 \pm 10 \\
(12-69)\end{array}$ & $<0.0001$ & ns & $<0.0001$ \\
\hline SPAP stress $(\mathrm{mmHg})$ & $\begin{array}{l}101 \pm 36 \\
(29-169)\end{array}$ & $\begin{array}{l}45 \pm 19 \\
(10-129)\end{array}$ & $\begin{array}{l}32 \pm 12 \\
(15-59)\end{array}$ & $<0.0001$ & 0.0001 & $<0.0001$ \\
\hline PVR rest (Wood U) & $\begin{array}{l}3.9 \pm 2.0 \\
(1.2-9.0)\end{array}$ & $\begin{array}{l}1.62 \pm 0.51 \\
(0.73-2.7)\end{array}$ & $\begin{array}{l}1.7 \pm 0.7 \\
(0.9-4.6)\end{array}$ & $<0.0001$ & ns & $<0.0001$ \\
\hline PVR stress (Wood U) & $\begin{array}{l}4.6 \pm 2.0 \\
(2.1-9.0)\end{array}$ & $\begin{array}{l}2.0 \pm 0.83 \\
(1.2-5.0)\end{array}$ & $\begin{array}{l}1.7 \pm 0.9 \\
(0.8-4.7)\end{array}$ & $<0.0001$ & ns & $<0.0001$ \\
\hline CO-based PVRI (L/min/mmHg) & $\begin{array}{l}1.0 \pm 0.95 \\
(0.23-5.4)\end{array}$ & $\begin{array}{l}1.57 \pm 0.47 \\
(0.74 \pm 2.7)\end{array}$ & $\begin{array}{l}4.28 \pm 2.3 \\
(0.49-10.8)\end{array}$ & 0.034 & $<0.0001$ & $<0.0001$ \\
\hline ESE time-based PVRI (min/mmHg) & $\begin{array}{l}0.66 \pm 0.39 \\
(0.27-2.1)\end{array}$ & $\begin{array}{l}1.89 \pm 1.47 \\
(0.31-10)\end{array}$ & $\begin{array}{l}3.95 \pm 2.26 \\
(0.8-11)\end{array}$ & $<0.0001$ & $<0.0001$ & $<0.0001$ \\
\hline
\end{tabular}

$A C T$ acceleration time of pulmonary flow, $C O$ cardiac output, $E S E$ exercise stress echocardiography, $N$ ' number of feasible measurements, $P V$ resistance pulmonary vascular resistance, $P V R I$ pulmonary vascular reserve index, SPAP systolic pulmonary artery pressure, TRV tricuspid regurgitant velocity

estimation of $\mathrm{CO}$ in echocardiography) or with the means of volumetric only $2 \mathrm{D}$ assessment of the left ventricle, but without detectable loss of information also with achieved workload or simpler exercise-time, an imaging independent proxy of cardiac output.

\section{Comparison with previous studies}

Several studies have shown the value of ACT for evaluation of pulmonary pressures (mean PA or SPAP) when TRV is not available, which happens frequently especially at peak exercise [8, 16, 28]. Our data are also consistent with previous evidences showing that pulmonary vascular resistance and reserve may be more informative than SPAP in identifying initial alterations of pulmonary hemodynamics [29, 30]. Simplified relationship between SPAP and exercise intensity have similar accuracy compared to direct measurements of $\mathrm{CO}$ in identifying an abnormal pulmonary vascular reserve, as shown by Claessens et al. in patients undergoing a simultaneous invasive assessment of pulmonary pressures [11]. In their study, an abnormal pulmonary reserve was identified as mPAP/CO slope by exercise CMR with invasive assessment of pressures. This method has superb accuracy but limited appeal in the clinical arena due to invasiveness and cost.

Yet, the noninvasive parameters which we proposed offered simple and highly accurate cut-offs for identification of $\mathrm{PH}$ patients with $\mathrm{CO}$-based PVRI $\leq 1.29$ and time-based $\mathrm{PVRI} \leq 1$ reflecting in an intuitive manner severely limited PVR, whereas the respective values $\leq 1.9$ and $\leq 1.7$ may indicate on early stage of pulmonary hypertension in which resting parameters are still near-normal. The availability of a highly feasible and simplified index is the prerequisite for large scale multicenter testing in the clinical arena $[12,13$, 20].

\section{Clinical implications}

Pulmonary hemodynamics is of utmost importance in the diagnosis, risk stratification and treatment in many cardiovascular conditions, from heart failure to pulmonary hypertension, extreme physiology and congenital heart disease [31, 32] with Doppler echocardiography being the most widely used screening tool in current clinical practice [14].

Yet, the noninvasive assessment of pulmonary hemodynamics with ESE does not find a relevant place in 


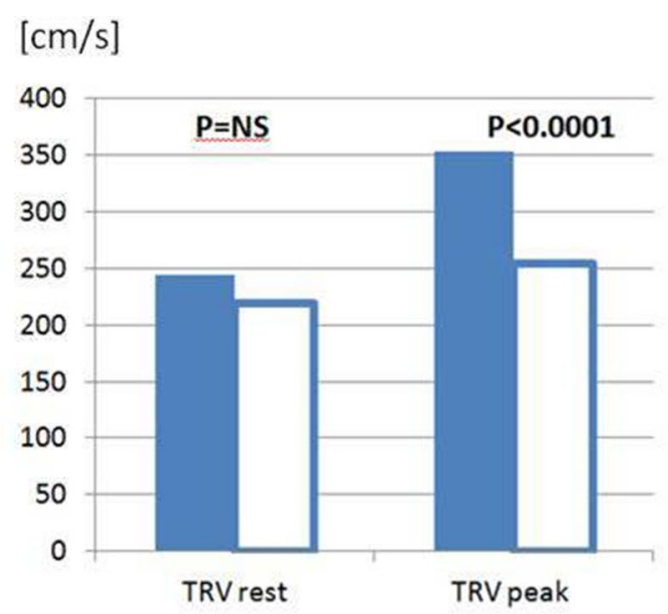

\section{[ms]}
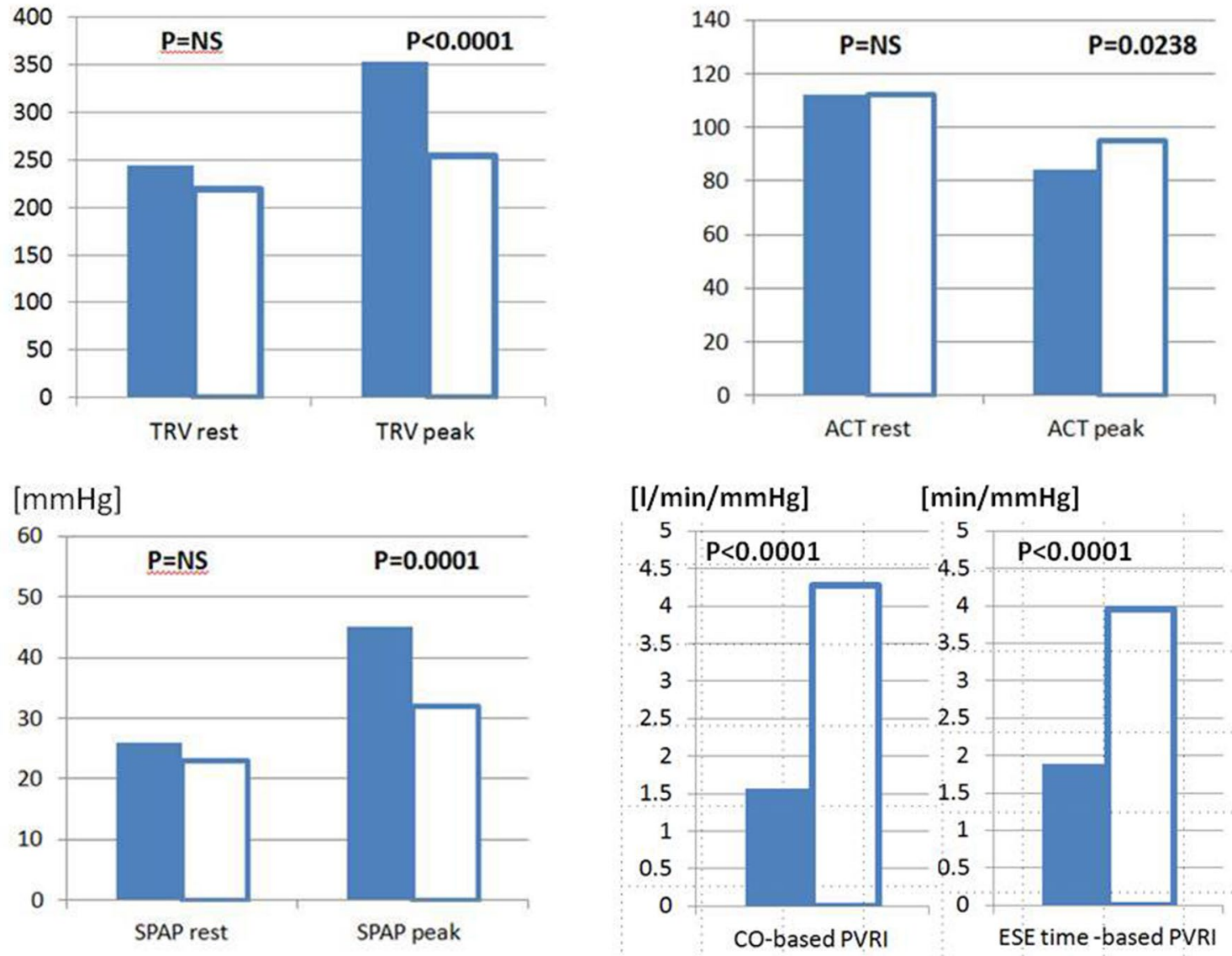

Fig. 6 The subgroup analysis- comparison between patients at risk of $\mathrm{PH}$ and controls. Bar graph showing the separation of the subgroup $\mathrm{PH}$ risk and controls, empty columns only by indices measured at peak ESE and pulmonary vascular reserve index. From left to right: TRV rest; TRV peak, $(\mathrm{cm} / \mathrm{s})$ ACT; rest, ACT peak (ms), SPAP rest,

SPAP peak (mmHg), CO-based PVRI (CO/SPAP*10 $\left.0^{-1}\right)(1 / \mathrm{min} /$ $\mathrm{mmHg})$; ESE time-based PVRI (ESE time/SPAP*10-1) $(\mathrm{min} / \mathrm{mmHg})$. $A C T$ acceleration time, $C O$ cardiac output, ESE exercise stress echocardiography, $P V R I$ pulmonary vascular reserve index, SPAP systolic pulmonary artery pressure, $T R V$ tricuspid regurgitant velocity
Table 4 Diagnostic value and cut- offs for flow dependent and independent parameters in the diagnosis of confirmed $\mathrm{PH}$, the results of the ROC analysis

\begin{tabular}{lllll}
\hline Parameter & AUC & Cut-off value & Sensitivity & Specificity \\
\hline SPAP (TRV based) stress (mmHg) & 0.964 & $>62$ & $96 \%$ & $89 \%$ \\
SPAP (TRV + ACT based) stress (mmHg) & 0.935 & $>69$ & $87 \%$ & $98 \%$ \\
CO-based PVRI (L/min/mmHg) & 0.922 & $\leq 1.29$ & $84 \%$ & $95 \%$ \\
ESE time-based PVRI (min/mmHg) & 0.949 & $\leq 1.0$ & $87 \%$ & $91 \%$ \\
\hline
\end{tabular}

$A C T$ acceleration time of pulmonary flow, $A U C$ area under curve, $C O$ cardiac output, ESE exercise stress echocardiography, $P V R I$ pulmonary vascular reserve index, SPAP systolic pulmonary artery pressure, TRV tricuspid regurgitant velocity evidence-based recommendations, in spite of the recognized conceptual merits of evaluating hemodynamics during stress which can unmask early disease [33]. European Society of Cardiology 2015 guidelines on pulmonary hypertension clearly state that "exercise echo has technical and methodological limitations and is NOT recommended for PH/PAH screening" (class of evidence III, level of recommendation
C) [2]. More recently, the 2019 European Society of Cardiology consensus recommendations on heart failure with preserved ejection fraction propose ESE with diastolic stress test in patients with intermediate probability on the basis of resting functional, morphologic and biochemical criteria, but also specify that peak TRV is only feasible in $50 \%$ of patients, cannot be used as a stand-alone criterion due to 


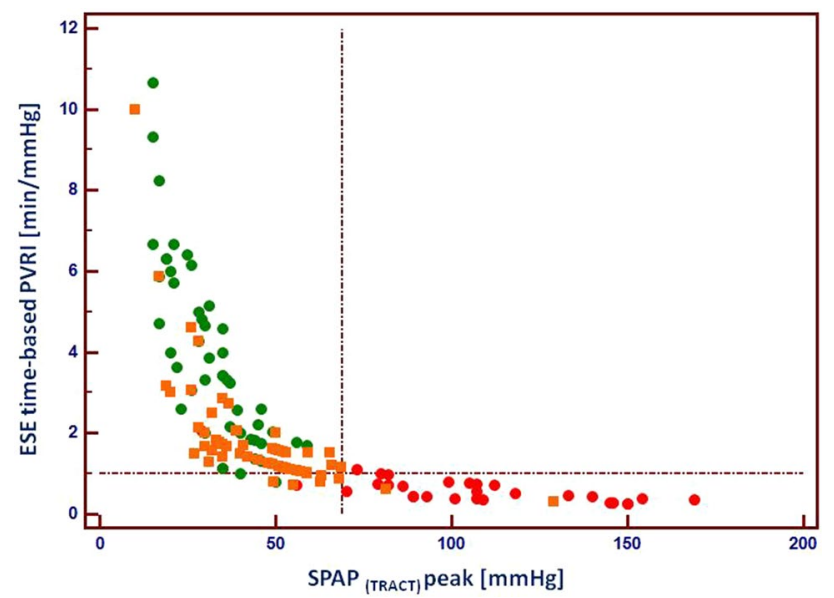

Fig. 7 The relationship between ESE-time based pulmonary vascular reserve index and SPAP achieved at peak ESE, showing clear separation of controls (green circles) and patients with confirmed PH (red circles). As far as group at risk of $\mathrm{PH}$ is concerned (orange squares) two patients showed SPAP at peak $>69 \mathrm{mmHg}$ whereas 11 patients displayed lowered pulmonary vascular reserve $<1 \mathrm{~min} / \mathrm{mmHg}$, which suggests higher sensitivity of this parameter for detection of early stage of pulmonary hemodynamics impairment. ESE exercise stress echocardiography, $P V R I$ pulmonary vascular reserve index, SPAP systolic pulmonary artery pressure, TRACT acronym for using TRV and ACT for SPAP estimation, vertical line indicates cut-off for SPAP $69 \mathrm{mmHg}$, horizontal line cut-off value for ESE time-based PRVI $1 \mathrm{~min} / \mathrm{mmHg}$, green circles - controls, orange squares-patients at risk of $\mathrm{PH}$, red circles - patients with confirmed $\mathrm{PH}$ its flow-dependence, and a peak TRV $>3.4 \mathrm{~m} / \mathrm{s}$ has some diagnostic value only when accompanied by E/e' $>15$ during exercise stress [34]. At least in principle, exercise-time based PVRI approach might remove the feasibility and conceptual barriers currently limiting an extensive ESE use in the clinical arena.

Despite its present limitations and with accordance to recent guidelines $[2,14]$ exercise stress echocardiography with noninvasive assessment of pulmonary pressure, resistance and right ventricular function should be considered in patients at high risk for PAH development as the adjunct tool exceeding the diagnostic potential of rest-only examination. Similarly, in patients with the established diagnosis of $\mathrm{PH}$, not showing the contraindications to exercise, noninvasive but quantitative assessment could improve monitoring of treatment and help further in prognostic stratification. Moreover, there are data showing that ESE, beyond the more technically demanding hypoxic challenge, may predict the risk of chronic mountain sickness (CMS) and high altitude pulmonary edema (HAPE) appearance [35]. Additionally, the adding the pulmonary parameters to the assessment of so called ,diastolic stress echo" have a potential for more detailed stratification of these the most prevalent etiology of ,secondary” PH [10], see Fig. 8 displaying the proposed role of the exercise stress in $\mathrm{PH}$ diagnosis.
Fig. 8 Proposed role of the exercise stress in $\mathrm{PH}$ diagnosis. $B N P$ brain natriuretic peptide, $C M S$ chronic mountain sickness, HAPE high altitude pulmonary edema, $H F P E F$ heart failure with preserved ejection fraction, $P A H$ pulmonary arterial hypertension, $P H$ pulmonary hypertension, $T R V$ tricuspid regurgitant velocity, TTE transthoracic echocardiography, $6 M W T$ six minute walk test

\section{The flow chart of exercise SE implementation with pulmonary parameters assessment}

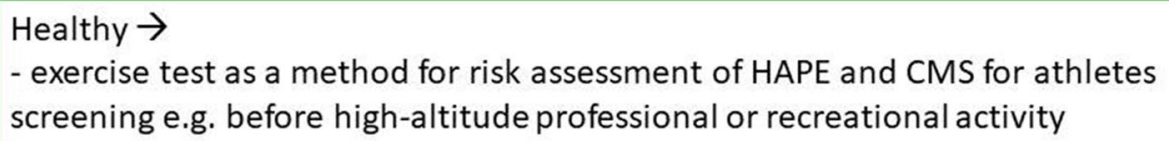

Patients at risk of $\mathrm{PAH} \rightarrow$

- exercise test as an adjunct to TTE screening for early PAH diagnosis

when TRV at rest $\leq 3.4 \mathrm{~m} / \mathrm{s}$ or was unfeasible

Patients with $\mathrm{PH}$ diagnosed $\rightarrow$

- exercise test for the enhancement of the functional status evaluation beyond

$6 \mathrm{MWT}$ result and BNP assessment in patients with WHO class I-III

- repetitive evaluation for monitoring of treatment and prognosis

Patients with exercise dyspnea without confirmation of elevated LAP during resting TTE $\rightarrow$

- exercise test enriched with pulmonary parameters in present indications for diastolic stress test (in HFPEF diagnosis) 


\section{Limitations}

Groups were not homogeneous, in particular with higher prevalence of women in the group of PH risk, due to the well known epidemiological profile of connective tissue disease. However, the pulmonary pressure response during exercise seems to be similar between men and women as has been recently published in metaanalysis of studies basing on right heart catheterisation [36]. Other possible confounders are intergroup inhomogeneities in BSA, smoking and cardiovascular drug usage, unavoidable when comparing group with different female to male ratio as well as different health status. However, the primary aim of the study concerning the feasibility assessment of the new proposed method, was unlikely affected by these confounders.

TRV and ACT have recognized limitations in the assessment of SPAP, including inadequate validation during exercise, need to include during exercise right atrial pressure typically assumed from inferior vena cava dimension and collapsibility at rest, possible heart rate-dependence for ACT.

The echocardiographers were not blinded to the study condition since the increased heart rate is associated with peak exercise. Also the acquisition of both parameters was not simultaneous but data were recorded in sequential manner.

Finally, we did not use saline microbubble injection as an attempt to enhance TRV spectrum since this maneuver requires intravenous injections and further complication of an already technically demanding ESE study.

\section{Conclusion}

Patients at risk for PH can be effectively separated from controls using transthoracic echocardiographic assessment during ESE. To achieve this clinically important goal, flow-independent indices such as CO-based PVRI or exercise time-based PVRI may be more effective than resting or stress indices such as SPAP. The feasibility of assessing PVRI is excellent if SPAP is obtained combining TRV or ACT, whenever TRV is not feasible, along with imagingindependent exercise-time used as a simple proxy of CO. This integrated approach allows to increase the success rate close to $100 \%$ and to adopt a more robust and more flowindependent assessment of pulmonary hemodynamics into practice.

Acknowledgements The study was supported by a travel Grant of Erasmus plus staff training mobility from Poland to Pisa for KWD (agreement number 33).

Author contributions KWD: gathering materials, performing echocardiography/ESE examinations, off-line analysis of parameters, statistical calculations and preparing the manuscript. JDK: participation in planning of the study, supervision and coordination of examinations, critical revision and correction of the manuscript. MDA: gathering materials, performing echocardiography/ESE examinations, revision and correction of the manuscript. GA: gathering materials, performing echocardiography/ESE examinations, revision and correction of the manuscript. AV: gathering materials, performing echocardiography/ESE examinations, revision and correction of the manuscript. FF: gathering materials, performing echocardiography/ESE examinations, revision and correction of the manuscript. MA: gathering materials, performing echocardiography/ESE examinations, revision and correction of the manuscript. QC: participation in planning of the study as well as revision and correction of the manuscript. EB: participation in planning of the study as well as revision and correction of the manuscript. EP: concept and planning of the study in the framework of SE 2020 project, experts advice and contribution in data analysis, writing and correcting of the manuscript.

Funding The work was partially supported in the framework of ERASMUS PLUS training grant for Staff received by KWD for travel and stay in CNR in Pisa. Beyond this, research did not receive any specific grant from funding agencies in the public, commercial, or not-for-profit sectors.

\section{Compliance with ethical standards}

Conflict of interest The authors declare that they have no conflict of interest.

Open Access This article is licensed under a Creative Commons Attribution 4.0 International License, which permits use, sharing, adaptation, distribution and reproduction in any medium or format, as long as you give appropriate credit to the original author(s) and the source, provide a link to the Creative Commons licence, and indicate if changes were made. The images or other third party material in this article are included in the article's Creative Commons licence, unless indicated otherwise in a credit line to the material. If material is not included in the article's Creative Commons licence and your intended use is not permitted by statutory regulation or exceeds the permitted use, you will need to obtain permission directly from the copyright holder. To view a copy of this licence, visit http://creativecommons.org/licenses/by/4.0/.

\section{References}

1. Rudski LG, Gargani L, Armstrong W, Lancellotti P, Lester S, Grunig E et al (2018) Stressing the cardiopulmonary vascular system: the role of echocardiography. J Am Soc Echocardiogr $31: 527-550$

2. Galiè N, Humbert M, Vachiery JL, Gibbs S, Lang I, Torbicki A, ESC Scientific Document Group et al (2016) 2015 ESC/ERS guidelines for the diagnosis and treatment of pulmonary hypertension: the joint task force for the diagnosis and treatment of pulmonary Hypertension of the European Society of Cardiology (ESC) and the European Respiratory Society (ERS): endorsed by: association for European Paediatric and Congenital Cardiology (AEPC), International Society for Heart and Lung Transplantation (ISHLT). Eur Heart J 37:67-119

3. Gruenig E, Weissman S, Ehlken N, Fijałkowska A, Fischer C, Fourme T et al (2009) Stress doppler echocardiography in relatives of patients with idiopathic and familial pulmonary arterial hypertension results of a multicenter European analysis of 
pulmonary artery pressure response to exercise and hypoxia. Circulation 119:1747-1757

4. Codullo V, Caporali R, Cuomo G, Ghio S, D'Alto M, Fusetti C et al (2013) Stress Doppler echocardiography in systemic sclerosis: evidence for a role in the prediction of pulmonary hypertension. Arthritis Rheum 65:2403-2411

5. Hachulla E, Gressin V, Guillevin L, Carpentier P, Diot E, Sibilia J et al (2005) Early detection of pulmonary arterial hypertension in systemic sclerosis: a French nationwide prospective multicentre study. Arthritis Rheum 52:3792-3800

6. Rudski LG, Lai WW, Afilalo J, Hua L, Handschumacher MD, Chandrasekaran K et al (2010) Guidelines for the echocardiographic assessment of the right heart in adults: a report from the American Society of Echocardiography endorsed by the European Association of Echocardiography, a registered branch of the European Society of Cardiology, and the Canadian Society of Echocardiography. J Am Soc Echocardiogr 23:685-713

7. Bossone E, Rubefire M, Bach DS, Ricciardi M, Armstrong WF (1999) Range of tricuspid regurgitation velocity at rest and during exercise in normal adult men: implications for the diagnosis of pulmonary hypertension. J Am Coll Cardiol 33:1662-1666

8. Wang YC, Huang CH, Tu YK (2018) Pulmonary hypertension and pulmonary artery acceleration time: a systematic review and meta-analysis. J Am Soc Echocardiogr 31:201-210

9. Wierzbowska-Drabik K, Picano E, Bossone E, Ciampi Q, Lipiec P, Kasprzak JD (2019) The feasibility and clinical implication of tricuspid regurgitant velocity and pulmonary flow acceleration time evaluation for estimating pulmonary pressure assessment during exercise stress echocardiography. Eur Heart J Cardiovasc Imaging 20:1027-1034

10. Lewis GD, Bossone E, Naeije R (2013) Pulmonary vascular hemodynamic response to exercise in cardiopulmonary diseases. Circulation 128:1470-1479

11. Claessens G, La Gerche A, Voigt J-U, Dymarkowski S, Schnell F, Petit T et al (2016) Accuracy of echocardiography to evaluate pulmonary vascular and right ventricular function during exercise. JACC Imaging 9:532-543

12. Picano E, Ciampi Q, Citro R, D’Andrea A, Scali MC, Cortigiani L et al (2017) Stress echo 2020: the international stress echo study in ischemic and non-ischemic heart disease. Cardiovasc Ultrasound $15: 3$

13. Ciampi Q, Zagatina A, Cortigiani L, Gaibazzi N, Borguezan Daros C, Zhuravskaya N et al (2019) Functional, anatomical, and prognostic correlates of coronary flow velocity reserve during stress echocardiography. J Am Coll Cardiol 74:2278-2291

14. Lancellotti P, Pellikka PA, Budts W, Chaudhry FA, Donal E, Dulgheru R et al (2016) The clinical use of stress echocardiography in non-ischaemic heart disease: recommendations from the European Association of Cardiovascular Imaging and the American Society of Echocardiography. Eur Heart J Cardiovasc Imaging 17:1191-1229

15. Lang RM, Badano LP, Mor-Avi V, Afilalo J, Armstrong A, Ernande L et al (2015) Recommendations for cardiac chamber quantification by echocardiography in adults: an update from the American Society of Echocardiography and the European Association of Cardiovascular Imaging. Eur Heart J Cardiovasc Imaging 16:233-270

16. Augustin DX, Coates-Bradshaw LD, Willis J, Harkness A, Ring L, Grapsa J et al (2018) Echocardiographic assessment of pulmonary hypertension: a guideline protocol from the British Society of Echocardiography. Echo Res Pract. https://doi.org/10.1530/ ERP-17-0071

17. Scali MC, Cortigiani L, Simionuc A, Gregori D, Marzilli M, Picano E (2017) Exercise-induced B-lines identify worse functional and prognostic stage in heart failure patients with depressed left ventricular ejection fraction. Eur J Heart Fail 19:1468-1478
18. Amsallem M, Sternbach JM, Adigopula S, Kobayashi Y, Vu TA, Zamanian $\mathrm{R}$ et al (2016) Addressing the controversy of estimating pulmonary arterial pressure by echocardiography. J Am Soc Echocardiogr 29:93-102

19. Yared K, Noseworthy P, Weyman AE, McCabe E, Picard MH, Baggish AL (2011) Pulmonary artery acceleration time provides an accurate estimate of systolic pulmonary arterial pressure during transthoracic echocardiography. J Am Soc Echocardiogr 24:687-692

20. Ciampi Q, Picano E, Paterni M, Daros CB, Simova I, e Silva JL, on behalf of Stress Echo 2020 et al (2017) Quality control of regional wall motion analysis in Stress Echo 2020. Int J Cardiol 249:479-485

21. Magnin PA, Stewart JA, Myers S, von Ramm O, Kisslo JA (1981) Combined Doppler and phased-array echocardiographic estimation of cardiac output. Circulation 63:388-392

22. Ihlen H, Amlie JP, Dale J (1984) Determination of cardiac output by Doppler echocardiography. Br Heart J 51:54-56

23. Lewis JF, Kuo LC, Nelson JG, Limacher MC, Quinones MA (1984) Pulsed Doppler echocardiographic determination of stroke volume and cardiac output: clinical validation of two new methods using the apical window. Circulation 70:425-431

24. Evangelista A, Garcia-Dorado D, Del Castillo H (1995) Cardiac index quantification by Doppler ultrasound in patients without left ventricular outflow tract abnormalities. J Am Coll Cardiol 25:710-716

25. Villavicencio C, Leache J, Marin J, Oliva I, Rodriguez A, Bodí M et al (2019) Basic critical care echocardiography training of intensivists allows reproducible and reliable measurements of cardiac output. Ultrasound J 11:5. https://doi.org/10.1186/s1308 9-019-0120-0

26. Abbas AE, Fortuin FD, Schiller NB, Appleton CP, Moreno CA, Lester SJ (2003) A simple method for noninvasive estimation of pulmonary vascular resistance. J Am Coll Cardiol 41:1021-1027

27. Venkateshvaran A, Hamade J, Kjellström B, Lund LH, Manouras A (2019) Doppler estimates of pulmonary vascular resistance to phenotype pulmonary hypertension in heart failure. Int $\mathrm{J}$ Cardiovasc Imaging 35:1465-1472

28. Kitabatake A, Inoue M, Asao M, Masuyama T, Tanouchi J, Morita T et al (1983) Noninvasive evaluation of pulmonary hypertension by a pulsed Doppler technique. Circulation 68:302-309

29. Roushdy AM, Ragab I, Abd el Raouf W (2012) Noninvasive assessment of elevated pulmonary vascular resistance in children with pulmonary hypertension secondary to congenital heart disease: a comparative study between five different Doppler indices. J Saudi Heart Assoc 24:233-241

30. Hellenkamp K, Unsöld B, Mushemi-Blake S, Shah AM, Friede T, Hasenfuss G et al (2018) Echocardiographic estimation of mean pulmonary artery pressure: a comparison of different approaches to assign the likelihood of pulmonary hypertension. J Am Soc Echocardiogr 31:89-98

31. Marra AM, Naeije R, Ferrara F, Vriz O, Stanziola AA, D’Alto M et al (2018) Reference ranges and determinants of tricuspid regurgitation velocity in healthy adults assessed by two-dimensional Doppler-echocardiography. Respiration 96:425-433

32. Naeije R, Saggar R, Badesch D, Rajagopalan S, Gargani L, Rischard F et al (2018) Exercise-induced pulmonary hypertension: translating pathophysiological concepts into clinical practice. Chest 154:10-15

33. Lau EMT, Humbert M, Celermajer DS (2015) Early detection of pulmonary arterial hypertension. Nat Rev Cardiol 12:143-155

34. Pieske B, Tschöpe C, de Boer RA, Fraser AG, Anker SD, Donal E et al (2019) How to diagnose heart failure with preserved ejection fraction: the HFA-PEFF diagnostic algorithm: a consensus recommendation from the Heart Failure Association (HFA) of the European Society of Cardiology (ESC). Eur Heart J 40:3297-3317 
35. Grunig E, Mereles D, Hildebrandt W, Swenson ER, Kübler W, Kuecherer H, Bärtsch P (2000) Stress Doppler echocardiography for identification of susceptibility to high altitude pulmonary edema. J Am Coll Cardiol 35:980-987

36. Esfandiari S, Wolsk E, Granton D, Azevedo L, Valle FH, Gustafsson F, Mak S (2019) Pulmonary arterial wedge pressure at rest and during exercise in healthy adults: a systematic review and meta-analysis. J Card Fail 25:114-122
Publisher's Note Springer Nature remains neutral with regard to jurisdictional claims in published maps and institutional affiliations. 